\title{
Infinite Regress and the Illusion of Actuality and Participation in Borges's The Aleph
}

\author{
Robin McAllister \\ Sacred Heart University, Fairfield, Ct. USA
}

Borges wants his reader to use imagination to participate in his fiction, to imagine the vision of the universe as an Aleph. The vision of the Aleph is paradoxical, impossible, inexpressible - a point in space, in the basement of a house in Buenos Aires, where all other points in the universe are simultaneously present. The reader sees the Aleph — or the illusion of the Aleph, watching it emerge as if through Borges' own eyes, as an unrequited lover and frustrated poet gradually accommodating the infinite vision to the limitations of actual perception. The illusion of actual presence the reader evokes seems to include the reader as both a subject reading and an object in the vision. The reader mirrors himself in the enumeration as the reader imaginatively projects associations and expectations into the images in order to make sense of them. The reader tries to avoid involving himself in the vision, but the images the writer presents the reader with are ambiguous, schematic, demanding intervention to try to resolve apparently unresolved contradictions by trying out the different interpretations that may make sense of them. Over and over again in reading the enumeration the reader encounters images that allow him to convert sequence into simultaneity, part into whole. Other images suggest the presence of infinite, multiple, perspectives on each object converging in the Aleph and reveal insights into hidden designs and into secret interiors of structures. The vision the reader reads must seem to exceed the limits of language and perception. Opposed to images of disintegration and chaotic dispersal are microcosmic images that suggest a whole reflected or contained in its parts, worlds reflected within worlds by infinite regress. Infinite regress undermines the assumption of a subject and object dichotomy in the act of reading and enhances the illusion of participation in the vision. Infinite regress, image within image, world within world, is a symmetry that asserts itself against the illusion of the enumeration as apparently random and chaotic and reinforces the illusion of infinite convergence on one point in space. The success of this illusion depends partly on Borges' success in finding a stylistic formula that encourages the reader to evoke a total, simultaneous vision from a partial, sequential listing of images. The I saw...I saw...I saw formula provides a minimal formal order for referring each separate image to the concept of a total vision without interfering with the illusion of actual participation by calling attention too much to the artifice that holds the vision together. Just as the separate images of the enumeration threaten to break loose from their minimal syntactical frame and assume autonomy of their own, so the enumeration itself seems to assume autonomy from its narrative context. Within the context of a story of failed mediation in which every attempt at communication is interrupted, aborted, or comically transformed into unanticipated consequences, the reader seems to have resolved the problem of poetics Borges the writer poses to him as a reader. The reader's reading of Borges' fiction is a kind of hypothesis the reader projects into his words in response to a problem of inexpressibility the writer poses for the reader just before he attempts to describe the Aleph. Similarly this fiction requires a certain kind of reader and reading-a 
reader who intervenes in the fiction to complete with our imagination what the writer only hints at or denies, and a reader who seeks out those contradictions or refutations in our interpretation that indicates our reading is only partial and falsifying, a hypothesis we propose in response to a problem of inexpressibility the writer has posed.

Keywords: Borges, Aleph, infinite regress

\section{Introduction}

Borges wants his reader to use imagination to participate in his fiction, to imagine the vision of the universe as an Aleph. The vision of the Aleph is paradoxical, impossible, inexpressible-a point in space, in the basement of a house in Buenos Aires, where all other points in the universe are simultaneously present.

\section{The Enumeration of the Aleph}

Here is how Borges describes the Aleph:

On the back part of the step, toward the right, I saw a small iridescent sphere of almost unbearable brilliance. At first I thought it was revolving; then I realized that this movement was an illusion created by the dizzying world it bounded. The Aleph's diameter was probably little more than an inch, but all space was there, actual and undiminished. Each thing (a mirror's face, let us say) was infinite things, since I distinctly saw it from every angle of the universe. I saw the teeming sea; I saw daybreak and nightfall; I saw the multitudes of America; I saw a silvery cobweb in the center of a black pyramid; I saw a splintered labyrinth (it was London); I saw, close up, unending eyes watching themselves in me as in a mirror; I saw all the mirrors on earth and none of them reflected me; I saw in a backyard of Soler Street the same tiles that thirty years before I'd seen in the entrance of a house in Fray Bentos; I saw bunches of grapes, snow, tobacco, lodes of metal, steam; I saw convex equatorial deserts and each one of their grains of sand; I saw a woman in Inverness whom I shall never forget; I saw her tangled hair, her tall figure, I saw the cancer in her breast; I saw a ring of baked mud in a sidewalk, where before there had been a tree; I saw a summer house in Adrogue and a copy of the first English translation of Pliny_Philemon Holland's — and all at the same time saw each letter on each page (as a boy, I used to marvel that the letters in a closed book did not get scrambled and lost overnight); I saw a sunset in Queretaro that seemed to reflect the color of a rose in Bengal; I saw my empty bedroom; I saw in a closet in Alkmaar a terrestrial globe between two mirrors that multiplied it endlessly; I saw horses with flowing manes on a shore of the Caspian Sea at dawn; I saw the delicate bone structure of a hand; I saw the survivors of a battle sending out picture postcards; I saw in a showcase in Mirzapur a pack of Spanish playing cards; I saw the slanting shadows of ferns on a greenhouse floor; I saw tigers, pistons, bison, tides, and armies; I saw all the ants on the planet; I saw a Persian astrolabe; I saw in the drawer of a writing table (and the handwriting made me tremble) unbelievable, obscene, detailed letters, which Beatriz had written to Carlos Argentino; I saw a monument I worshiped in the Chacarita cemetary; I saw the rotted dust and bones that had once deliciously been Beatriz Viterbo; I saw the circulation of my own dark blood; I saw the coupling of love and the modification of death; I saw the Aleph from every point and angle, and in the Aleph I saw the earth and in the earth the Aleph and in the Aleph the earth; I saw my own face and my own bowels; I saw your face; and I felt dizzy and wept, for my eyes had seen that secret and conjectured object whose name is common to all men but which no man has looked upon—-the inconceivable universe (Rodriguez Monegal \& Reid, 1981, p. 161).

The reader sees the Aleph—or the illusion of the Aleph, watching it emerge as if through Borges' own eyes, as an unrequited lover and frustrated poet gradually accommodating the infinite vision to the limitations of actual perception. As the reader's I merges with the narrator's $I$, the reader is so caught up in the incantatory power of the I saw...I saw enumeration that the reader seems to experience the vision as an eyewitness. At some point in reading this $I$ saw...I saw enumeration of some 35 images, the reader begins to create or-re-create-an illusion of the Aleph as a microcosm, a little world within the world, in which what is normally experienced sequentially in time appears as if simultaneous and in which the part somehow contains 
the whole. At some point in the reading of the enumeration the reader ceases to be aware of reading Borges' description of the Aleph, of being able to maintain the conscious distinction between the reader and the fiction being read. The reader surrenders to the illusion of actually participating in the vision.

The reader converts the writer's description into the reader's own evocation. Soon the reader becomes more than an eyewitness to the Aleph. If the reader seems to start out only a listener or silent observer, separate from the vision, listening to Borges begin to describe it, by the end of the vision the reader is part of the Aleph. The writer confirms and symbolizes the reader's presence in the vision by one of the images of the enumeration: "I saw your face." If the reader can accept the logical consequence of this imaginative possibility, that is, if the reader can be both a reader, separate from the world of the fiction, and yet a participant included in the fiction, then the reader's status as reader is a paradoxical denial of the commonly assumed dichotomy between subject and object. The reader participates in an infinite regress in the enumeration being read. The illusion of actual presence the reader evokes seems to include the reader as both a subject reading and an object in the vision. The reader mirrors himself in the enumeration as the reader imaginatively projects associations and expectations into the images in order to make sense of them.

The reader tries to avoid involving himself in the vision, but the images the writer presents the reader with are ambiguous, schematic, demanding intervention to try to resolve apparently unresolved contradictions by trying out the different interpretations that may make sense of them. To see or imaginatively recreate the images, the reader first has to think about them, puzzle them out according to the reader's own preconceptions about the Aleph, aided by prior familiarity with figures of speech, fictional convention, and literary allusion. Thus, an image like "I saw the teeming sea" appeals less to the ability to call up an immediate memory of some visual aspect of an actual ocean than to the previous concept of the Aleph as somehow containing "all space...actual and undiminished,” (Rodriguez Monegal \& Reid, 1981, p. 159) as Daneri had stammered out in despair over the telephone to Borges when the house on Garay Street containing the Aleph is threatened with demolition. Such an image is schematic in the sense of functioning as a diagram or puzzle to interpret before the reader assigns a sensual content to it in the form of a remembered image from actual experience or from reading. The reader does find, however, more precisely visualizable images, such as "I saw a silvery cobweb in the center of a black pyramid," but even this image functions within the reader's previously acquired conceptual context of microcosm. It represents a secret or hidden miniature structure within a larger one. It leaves the exact nature of its image up to the reader's own actual memories and associations with spiderwebs and pyramids.

Over and over again in reading the enumeration the reader encounters images that allow him to convert sequence into simultaneity, part into whole. "I saw daybreak and nightfall” makes simultaneously present to me two phenomena we ordinarily experience separately and sequentially, as does "I saw night and the contemporary day." Similarly, "I saw in a backyard of Soler Street the same tiles that thirty years before I'd seen in the entrance of a house in Fray Bentos" suggests an autobiographical, memory analogue that converts sequence into simultaneity and difference into identity, for the narrator's memory image is identical with the image of present-moment perception. "I saw a sunset in Queretaro that seemed to reflect the color of a rose in Bengal” unites otherwise disparate elements into a metonymic unity.

Other images suggest the presence of infinite, multiple, perspectives on each object converging in the Aleph and reveal insights into hidden designs and into secret interiors of structures. If in the spider-web-in-the-pyramid image the reader imagines something very tiny seen close up from a perspective 
looking out from the interior of something very large, dark, and geometrical, the image, "I saw a splintered labyrinth (it was London)" appeals to the vertical sense of visual perspective as if the reader saw the city from a vast height. Something very large is seen very small, from the outside looking down, revealing a secret pattern inaccessible to the reader ordinarily wandering along a city street.

The image of a broken labyrinth symbolizes another aspect of the reader's process of reading the enumeration. At times the reader's attention is confused, hesitates, wanders as the reader copes with the multiple demands these images make on his reading responses. The reader can only retain the images together in a total vision by a deliberate interpretive effort. His attention is constantly in danger of dispersing chaotically among the disparate, separate images of the enumeration, each of which demands its own interpretive reconstruction to make sense of it as a part of the whole Aleph. At times this threat of immanent dispersal overwhelms and obstructs the continuity of the act of reading.

The vision the reader reads must seem to exceed the limits of language and perception. The vision the enumeration reveals is not an ordered, harmonious cosmos, but a universe that is chaotic, a congeries of disparate, apparently incongruous, merely juxtaposed objects converging on one point, the Aleph. (Daneri had praised a line in his own inept version of the vision, an attempt to copy the infinite vision of the Aleph in infinite, unfinished verses: "The second flows from Homer to Hesiod, generous homage, at the very same outset, to the father of didactic poetry, not without rejuvenating a process whose roots go back to Scripture-enumeration, congeries, conglomeration”) (Rodriguez Monegal, \& Reid, 1981, p. 156). The stylistic order of the enumeration is not inherent in or copied from the Aleph (if language and vision are incommensurate), but is a deliberately constructed artifice (an "equivalent image") to which the infinite randomness of the Aleph is accommodated. The enumeration cannot appear too selected and ordered, then, and its stylistic formula, I saw...I saw...I saw, seems to frame a random, arbitrary selection of infinite images that exceed and evade any attempt to impose a stylistic order on them. Astonishingly, the enumeration consists of a single, vast sentence. The enumeration of infinite images expands the syntactic structure of the sentence beyond its usual limits. "In that single, gigantic instant," Borges says, "I saw millions of acts both delightful and awful" (Rodriguez Monegal \& Reid, 1981, p. 161). At times even this minimal order seems precarious, in danger of being overwhelmed by the infinite convergence of infinite objects in the Aleph.

Parenthetical interruptions in the repetition of the I saw...I saw pattern run the risk of dispelling the illusion of total vision the syntactical structure of the enumeration reinforces. Almost at the exact center of the enumeration Borges interrupts his description of Philemon Holland's translation of Pliny to insert the parenthetical image of a closed book whose letters wander and lose themselves during the night when the book is not read: "I saw a summer house in Adrogue and a copy of the first English translation of Pliny-Philemon Holland's - and all at the same time saw each letter on each page (as a boy, I used to marvel that the letters in a closed book did not get scrambled and lost overnight)." This book image is Borges’ parody of Dante's vision of God in Paradiso xxxiii, 86, where the universe, perceived as immanent in God's Presence, appears to Dante as an ordered, harmonious Book binding together the infinite "accidents" and "substances" of the universe like the pages of a book bound in one volume (Dante Alighieri, 1961, p. 363). Borges' parodyforces the reading of the enumeration to move between the extremes of particular, apparently chaotic images that exceed any attempt at order and total structure on the one hand and, on the other, the impression of a total vision governing these images. Pliny's Geography symbolizes both an immanent and imminent dispersal threatening the reader's illusion of total vision. 
Like earlier images of dawn and afternoon, night and contemporaneous day, the Pliny image is also a figure for the simultaneity of elements, letters on a page that are ordinarily encountered sequentially and separately. Pliny's book, an attempt to describe the surface of the world, is thus an analogue to Daneri's "The Earth,” Borges' enumeration, and the Aleph itself. The book stands for a macrocosmic total vision, while the separate letters are microcosmic. The entire image suggests the figure of infinite regress that appears and reappears throughout the enumeration as a way of suggesting infinity. Why would the letters in a "closed" book disperse and lose themselves in the night? Because the reader is no longer reading the book, sustaining its separate elements in an act of reading. If so, this closed book prefigures the reader's own effort to read the enumeration in a way that evokes and sustains an illusion of total vision from a reading of its separate images.

Opposed to images of disintegration and chaotic dispersal are microcosmic images that suggest a whole reflected or contained in its parts, worlds reflected within worlds by infinite regress, as in the Pliny above. "I saw convex equatorial deserts and each one of their grains of sand" combines a macrocosmic vista with a suggestion of infinite microcosmic ones. A more obviously microcosmic image occurs in "I saw in a cabinette in Alkmaar a terrestrial globe between two mirrors that multiplied it endlessly.” This actual scale model miniature world infinitely reflected between mirrors offers a real analogue to the logical, fictional version of infinite regress that predetermines the problem of poetics Borges poses for the reader to resolve.

Infinite regress undermines the assumption of a subject and object dichotomy in the act of reading and enhances the illusion of participation in the vision. An earlier image implies such an infinite regress: "I saw, close up, unending eyes watching themselves in me as in a mirror.” As a subject seeing, the reader sees himself as an object reflected between mirrors, or, in the image of the eyes mirroring themselves within the observer's eyes. How can the reader distinguish the eyes seeing from the eyes seen? Infinite regress, image within image, world within world, is a symmetry that asserts itself against the illusion of the enumeration as apparently random and chaotic and reinforces the illusion of infinite convergence on one point in space.

Repetition by chiasmus, a crossing over or exchange of relations, is a temporal, sequential form infinite regress also assumes. Toward the end of the enumeration, this pattern of infinite regress focuses the reader's attention on the Aleph as microcosm in which all the images of the universe converge: "I saw the Aleph from every point and angle, and in the Aleph I saw the earth and in the earth the Aleph and in the Aleph the earth.” Distinctions between subject and object no longer apply as the reader nears the end of the enumeration. Borges sees himself in the vision as in a mirror- "I saw my own face and my bowels"-and, even more startling, there is no longer a distinction between the reader and the enumeration being read. The reader is suddenly included in an intense illusion of unmediated vision when Borges mentions "I saw your face."

The success of this illusion depends partly on Borges' success in finding a stylistic formula that encourages the reader to evoke a total, simultaneous vision from a partial, sequential listing of images. His paratactic I saw...I saw...I saw formula accommodates itself to an illusion of simultaneous, total, convergence in a single act of vision. If Borges had wished to signal sequence and articulate separate relationships between images, he might have written "I saw...after I saw...then I saw," but his I saw...I saw...I saw juxtaposes the separate images of the enumeration without causal, temporal, or relational connectives. By omitting such hypotactic connectives, Borges suggests that no particular I saw has causal, temporal, or spatial priority over any other. The repetition does not symbolize a sequence of visual acts, but refers each image back to a single visual act. Each I saw potentially occupies the same point in time and space "without overlapping or transparency,” (Rodriguez Monegal \& Reid, 1981, p. 161) as Borges already observed about the Aleph itself. 
This I saw...I saw...I saw formula provides a minimal formal order for referring each separate image to the concept of a total vision without interfering with the illusion of actual participation by calling attention too much to the artifice that holds the vision together. Without the order of the enumeration, the particular images would have no identity within the vision, no frame of reference, but without the particular images the reader's concept of the Aleph would remain a mere conceptual abstraction without sensory substance. The repetition of the I saw focuses the reader's interpretation of the images on the Aleph, but, as the identical formula is repeated, the reader no longer needs to attend to it consciously. The reader begins to interiorize what previously had to be attended to self-consciously, and each image begins to focus the reader's prior associations and preconceptions of the Aleph. The images — or the situations or objects they stand for-seem to stand out from the syntactic frame of the enumeration, intensely present to the reader's conscious attention, almost asserting an actual existence autonomous from the fiction. In reading the enumeration, then, the reader focuses on the intense reality of the images because the reader no longer has to attend to their explicit relation to the Aleph. Meaning and reference become implicit in the reader's response and do not distract attention from the actuality of the images by calling the reader's attention to the rhetorical artifice that holds the enumeration together.

Just as the separate images of the enumeration threaten to break loose from their minimal syntactical frame and assume an autonomy of their own, so the enumeration itself seems to assume an autonomy from its narrative context, as if the fictional story as a whole were only an arbitrarily constructed frame, a pretext, to set off and release the vision of the Aleph as an overwhelming, autonomous presence. Rodriguez Monegal \& Reid asserts this autonomy by characterizing the enumeration of the Aleph as a "prose poem" (Rodriguez Monegal \& Reid, 1981, p. 351, n. 51).

The incantatory I saw...I saw...I saw catches the reader up into a mode of reality completely remote from the pedantic, ironically distanced atmosphere of the narrative within which the enumeration is set. The reader has temporarily left the pompous, slightly ridiculous, literary discussions in the Gothic mansion on Garay Street far behind. The vision of the Aleph seems to exceed even its fictional context, or, at least, to the extent that the reader is able to focus attention on the vision the reader is evoking rather than focusing on the verbal artifice that makes the vision possible, the Aleph assumes an autonomous presence for the reader, an illusion that resembles the apparent reality of a dream when the reader in the state of dreaming. Only when the reader awakens does he realize the events he seems to have been participating in have been only the reader's own creation. The reader's reading resembles a partly conscious, voluntary dreaming in which the reader evokes images and seems to participate in situations without explicit awareness of himself as the source of their apparently independent existence, an autonomous presence that seems to exist apart from the reader and yet include him.

Within the context of a story of failed mediation in which every attempt at communication is interrupted, aborted, or comically transformed into unanticipated consequences, the reader seems to have resolved the problem of poetics Borges the writer poses to him as a reader. Despite the writer's denial that he can use words to convey the Aleph to the reader, the vision the reader evokes from the reading of the enumeration resolves the writer's despair and, contrary to the will of the gods, achieves an impossible collaboration between writer, equivalent image, vision, and reader. Never before has a reader felt so powerful, so autonomous.

\section{Inexpressibility}

The reader's reading of Borges' fiction is a kind of hypothesis the reader projects into his words in 
response to a problem of inexpressibility the writer poses for the reader just before he attempts to describe the Aleph:

I arrive now at the ineffable core of my story. And here begins my despair as a writer. All language is a set of symbols whose use among its speakers assumes a shared past. How, then, can I translate into words the limitless Aleph which my floundering mind can scarcely encompass? Mystics, faced with the same problem, fall back on symbols: to signify the godhead, one Persian speaks of a bird that somehow is all birds; Alanus de Insulis, of a sphere whose center is everywhere and circumference is nowhere; Ezekiel, of a four-faced angel who at one and the same time moves east and west, north and south. (Not in vain do I recall these inconceivable analogies; they bear some relation to the Aleph.) Perhaps the gods might grant me a similar metaphor, but then this account would become contaminated by literature, by fiction. Really, what I want to do is impossible, for any listing of an endless series is doomed to be infinitesimal. In that single gigantic instant I saw millions of acts both delightful and awful; not one of them amazed me more than the fact that all of them occupied the same point in space, without overlapping or transparency. What my eyes beheld was simultaneous, but what I shall now write down will be successive, because language is successive. Nonetheless, I'll try to recollect what I can. (Rodriguez Monegal \& Reid, 1981, pp. 160-161)

\section{Conclusion}

As the reader reads Borges' enumeration of the images of the Aleph, his reading functions somewhat like an hypothesis, testing the authenticity of his version, against the paradoxes and limitations he has already placed on expressing the vision: using words to express a vision that is incommensurate with words, making the sequentiality of language express the simultaneity of vision, the particularity of language express the totality of vision. An authentic fiction, a fiction that expresses an authentic vision of the Aleph, cannot just copy the vision, it must use symbol or metaphor. The writer needs to construct a fiction that not only converts sequence into simultaneity and partiality into totality, but prevents the reader, from confusing the symbol with the thing symbolized, confusing the Aleph with the artifice Borges uses to mediate the vision. This function of fiction constitutes a poetics of fiction. Similarly this fiction requires a certain kind of reader and reading - a reader who intervenes in the fiction to complete with our imagination what the writer only hints at or denies, and a reader who seeks out those contradictions or refutations in our interpretation that indicates our reading is only partial and falsifying, a hypothesis we propose in response to a problem of inexpressibility the writer has posed for us.

\section{References}

Borges, J. L. (1970). The aleph and other stories 1933-1969: together with commentaries and an autobiographical essay. (N. T. di. Giovanni, Ed. \& Trans.) New York: Bantam.

Dante Alighieri. (1961). The Paradiso. (J. Ciardi, Trans.) New York: Mentor.

Rodriguez Monegal, E. (1972). Borges: The reader as writer. TriQuarterly, 25, 102-143.

Rodriguez Monegal, E., \& Reid, A. (Eds.) (1981). Borges, a reader: A selection from the writings of Jorge Luis Borges. E. M. Rodriguez \& A. Reid (Eds.). New York: Dutton. 